\title{
Blood Pressure and Vascular Effects of Leptin in Humans
}

\author{
ROBERT D BROOK M.D., ${ }^{1}$ ROBERT L BARD M.A., ${ }^{1}$ PETER F BODARY Ph.D., ${ }^{1}$ \\ DANIEL T EITZMAN M.D., ${ }^{2}$ SANJAY RAJAGOPALAN M.D., ${ }^{3}$ YAN SUN M.S., ${ }^{3}$ \\ and ALEX M DEPAOLI M.D. ${ }^{1}$
}

\begin{abstract}
Background: Leptin may play a role in mediating obesity-related hypertension. However, its effects on the vasculature and blood pressure (BP) remain poorly defined in humans.

Methods: In the first study, we performed a short-term, placebo-controlled, randomized, double-blind, cross-over experiment investigating the actions of recombinant human leptin (r-metHuLeptin) in 15 nonobese adults. To compliment the acute study, we retrospectively analyzed available BP results from a previously performed 85-day, placebo-controlled, randomized, double-blind, parallel weight-loss study using r-metHuLeptin in 284 obese adults.

Results: In the acute study, conduit artery endothelial function determined by brachial flowmediated dilatation (FMD) increased 2 hours following $0.2 \mathrm{mg} \cdot \mathrm{Kg}^{-1}$ subcutaneously (SC) of $\mathrm{r}-\mathrm{metHuLeptin}$ versus placebo $(+3.3 \%$ versus $-2.8 \%, P=.02)$. BP remained unchanged 4 hours after injections. In the retrospective analysis of the weight loss study data, $10 \mathrm{mg}$ every day before noon (QAM), $10 \mathrm{mg}$ every day after noon (QPM), or $10 \mathrm{mg}$ twice a day (BID) SC of $\mathrm{r}$-metHuLeptin was found to not alter the degree of weight loss $(-3.2 \pm 3.7$ versus $-2.9 \pm 3.2$ $\mathrm{Kg}, P=.54)$, change in systolic $(-1.6 \pm 12.9$ versus $-2.0 \pm 13.9 \mathrm{mmHg}, P=.85)$ and diastolic $\mathrm{BP}(-0.2 \pm 8.7$ versus $-1.5 \pm 8.6, P=.30)$, as well as heart rate $(-1.4 \pm 10.7$ versus $-1.4 \pm$ 10.4 beats $/ \mathrm{min}, P=.98)$ compared to placebo.

Conclusions: In our acute study, marked hyperleptinemia rapidly enhanced endothelial function and did not alter BP. The available data from a longer-term study in healthy obese adults did not demonstrate a significant effect of hyperleptinemia upon BP. These combined findings do not support a direct role for leptin in linking obesity to hypertension, however more studies are required to corroborate these observations.
\end{abstract}

\section{INTRODUCTION}

$\mathbf{H}$ YPERLEPTINEMIA MAY BE A MECHANISM linking obesity with hypertension. ${ }^{1,2}$ Leptin is secreted by adipocytes and modulates sympathetic nervous system activity to regulate body weight. Therefore, a potential consequence of hyperleptinemia may be elevated arterial blood pressure (BP). These autonomic actions are countered by direct leptin-mediated vasodilatation. "Selective tissue resistance" to leptin may promote chronic hypertension in human obesity if its pressor actions remain sensitive while the vasodilatory responses are blunted.

${ }^{1}$ Cardiovascular Medicine Division, University of Michigan, Ann Arbor, MI

${ }^{2}$ Mount Sinai School of Medicine, New York, NY

${ }^{3}$ Amgen Inc, Thousands Oaks, CA 
2,4 Indeed, several animal experiments have demonstrated that leptin sub-acutely causes a net increase in BP. ${ }^{4,5}$ Leptin's hemodynamic actions remain incompletely described in humans, therefore the aim of this study was to investigate the direct effect of leptin on BP and vascular function in healthy adults.

\section{METHODS}

Two separate experiments following use of recombinant methionyl human leptin ( $\mathrm{r}-$ metHuLeptin) (Amgen Inc, Thousand Oaks, CA) were performed. The acute study was prospectively performed at the University of Michigan and approved by its Institutional Review Board. Fifteen healthy nonsmoking adults with a body mass index $(\mathrm{BMI})<27 \mathrm{~kg} \cdot \mathrm{m}^{-2}$ and without cardiovascular risk factors signed informed consent and were enrolled. None of the participants were taking any medication known to alter BP or endothelial function. Subjects entered into a randomized, double-blind, cross-over study (2 week washout) of r-metHuLeptin $0.2 \mathrm{mg} \cdot \mathrm{kg}^{-1} \mathrm{SC}$ versus placebo (sorbitol and sodium acetate, $\mathrm{pH} 4.0$, of the same volume). Subjects fasted more than 8 hours overnight, had brachial artery flow mediated dilatation (FMD) performed, ${ }^{6}$ and had blood drawn before and 2 and 4 hours after injections. Three seated BP values in the dominant arm were measured (Omron 711AC, Omron Healthcare, Inc., Bannockburn, IL). and averaged at the start and at the 4 hour time point.

As far as we are aware, there have been no published data on the long-term effects of leptin on $\mathrm{BP}$ in humans. In order to complement the results of the acute study findings, to gain insight into the more biologically important long-term actions of leptin, we obtained permission from the investigative team (A.M.D., Amgen Inc, Thousand Oaks, CA) to analyze the BP results (which had not been published) from a previously performed weight loss study. This chronic study was conducted in obese subjects from September 1997 to August 1998 at 8 clinics in the Netherlands, Sweden, and the United Kingdom. Subjects were otherwise healthy adults, with the exception of obesity. Those with comorbidities such as drugtreated diabetes, hyperlipidemia, and uncontrolled hypertension were excluded. All subjects provided written informed consent, and an independent Ethics Committee at each study site approved the protocol. Subjects were randomly assigned in a 1:1:1 allocation to 3 different treatment regimens of r-metHuLeptin or matching placebo allocated 3:1 (active drug:placebo) within each regimen (10 $\mathrm{mg}$ subcutaneously [SC] daily before noon [QAM], or $10 \mathrm{mg}$ SC daily after noon [QPM], or $10 \mathrm{mg}$ SC twice a day [BID]). Obese subjects with a BMI between 27.5 and $37.0 \mathrm{~kg}$. $\mathrm{m}^{-2}$ were enrolled in a 3-week dietary lead-in phase in which subjects were prescribed a 2100 $\mathrm{kJ} \cdot$ day $^{-1}\left(500 \mathrm{kcal} \cdot\right.$ day $\left.^{-2}\right)$ deficit diet. All subjects received single-blinded placebo injections throughout the dietary lead-in phase. Only subjects with a weight loss between 0 and $5.0 \mathrm{~kg}$ and a BMI over $25.0 \mathrm{~kg} \cdot \mathrm{m}^{-2}$ were eligible to continue into the treatment phase. Subjects were then randomized into the 3 treatment regimens in a stratified fashion according to body weight loss during the dietary lead-in $(<2.0 \mathrm{~kg}$ or $\geq 2.0 \mathrm{~kg}$ ). Drug or placebo was self administered SC during the study. Fasting BP was measured in the morning (7-9 am) at the start and end of the treatment phase by standardized methods across sites. Subjects rested in a sitting position for 5 minutes and a single BP was measured by ausculatation using appropriate-sized arm cuffs and resting heart rate was determined. Blood was then drawn for fasting plasma leptin levels.

In our acute study, BP responses were compared by paired t-test. FMD values at the 0,2 ,

Table 1. Patient Characteristics Enrolled IN THE Acute Study

\begin{tabular}{lc}
\hline & $\begin{array}{c}\text { Mean } \pm S D \\
(n=14)\end{array}$ \\
\hline Age (years) & $26 \pm 7$ \\
Male/Female (no.) & $6 / 9$ \\
Body Weight $(\mathrm{kg})$ & $70 \pm 16$ \\
Systolic Blood Pressure $(\mathrm{mm} \mathrm{Hg})$ & $112 \pm 12$ \\
Diastolic Blood Pressure $(\mathrm{mm} \mathrm{Hg})$ & $66 \pm 8$ \\
Total Cholesterol $\left(\mathrm{mg}^{-1} \mathrm{dL}^{-1}\right)$ & $157 \pm 32$ \\
High Density Lipoprotein $\left(\mathrm{mg} \cdot \mathrm{dL}^{-1}\right)$ & $60 \pm 15$ \\
Low Density Lipoprotein $\left(\mathrm{mg} \cdot \mathrm{dL}^{-1}\right)$ & $78 \pm 25$ \\
Triglycerides (mg $\left.\cdot \mathrm{dL}^{-1}\right)$ & $97 \pm 82$ \\
Race & \\
$\quad$ Caucasians & 9 \\
$\quad$ African-Americans & 2 \\
$\quad$ Asians & 3 \\
Ethnicity & \\
$\quad$ Hispanic & 0 \\
$\quad$ Non-Hispanic & 14 \\
\hline
\end{tabular}


Table 2. Blood Pressure Responses in the Acute Study, $\mathrm{N}=14$, All $P>.05$

\begin{tabular}{llcr}
\hline & \multicolumn{1}{c}{ Treatment } & Baseline & 4 hour \\
\hline Placebo & Systolic Blood Pressure (mm Hg) & $112 \pm 10$ & $112 \pm 10$ \\
& Diastolic Blood Pressure (mm Hg) & $66 \pm 7$ & $66 \pm 9$ \\
r-metHul & Systolic Blood Pressure (mm Hg) & $113 \pm 13$ & $115 \pm 14$ \\
& Diastolic Blood Pressure (mm Hg) & $66 \pm 9$ & $65 \pm 10$ \\
\hline
\end{tabular}

$\mathrm{BP}$ was measured only at the 4 hour time point post injections

and 4 hour time points were compared by a mixed effects model adjusted for effects of sequence, period, treatment, and time. Change in plasma leptin was correlated to the change in FMD by Pearson correlation coefficient. In the retrospective analysis of the previously performed chronic study, the data on file were obtained from the company and weight loss and $\mathrm{BP}$ changes were compared by independent samples t-tests. Values are expressed as mean $+/-$ SD and significance was defined as $P<.05$ for all tests.

\section{RESULTS}

The characteristics of the patients in the acute study are shown in Table 1 . There were no significant changes in BP 4 hours after r-metHuLeptin injection compared to placebo
(Table 2). Data on 1 patient were lost and not included. Figure 1 demonstrates that brachial FMD was significantly enhanced by r-metHuLeptin after 2 hours and trended towards an increase at 4 hours. Mean plasma leptin concentrations increased from a normal baseline value of $9.0 \pm 6.8$ to $135 \pm 39.3 \mathrm{ng}$. $\mathrm{mL}^{-1} 2$ hours after $\mathrm{r}$-metHuLeptin injection. The increase in leptin $\left(\right.$ mean $\left.=126.4 \mathrm{ng} \cdot \mathrm{mL}^{-1}\right)$ correlated to the change in brachial FMD at 2 hours $(\mathrm{r}=0.52, P=.059)$.

Table 3 shows the baseline characteristics of the patients that were previously enrolled in the long-term weight loss study. There were no changes in basal brachial artery diameter after leptin. The reductions in weight, BP and heart rate did not differ significantly between groups (Table 4). Baseline mean plasma leptin was the same for each group $\left(19 \pm 14 \mathrm{ng} \cdot \mathrm{mL}^{-1}\right)$, however, levels at day 85 were higher in the r-

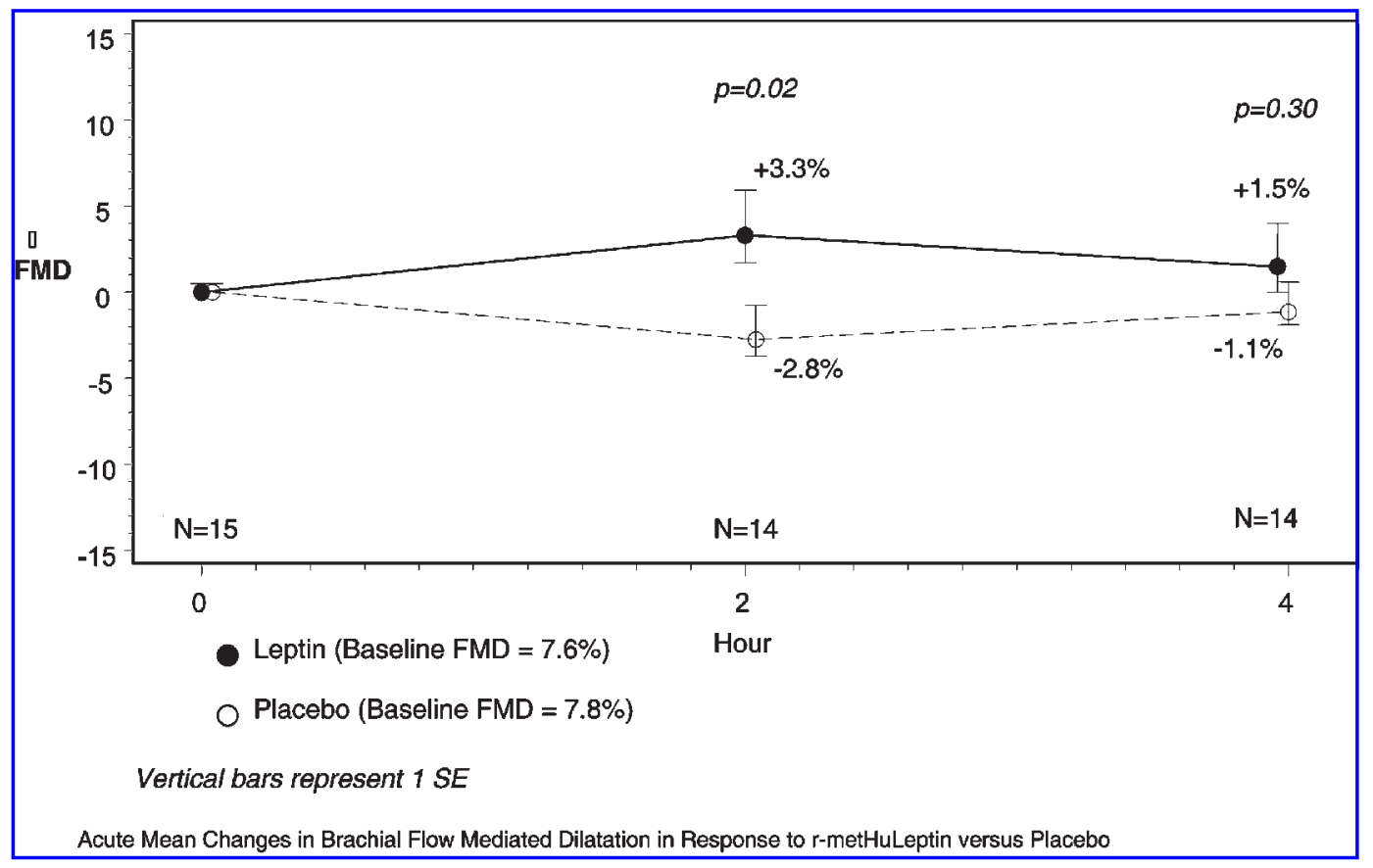

FIG. 1. Acute mean changes in brachial flow mediated dilatation in response to r-metHuLeptin versus placebo. 
Table 3. Baseline Demographics of Patients in the Chronic Study

\begin{tabular}{|c|c|c|c|c|c|c|c|c|}
\hline & & \multicolumn{3}{|c|}{ Placebo } & \multicolumn{3}{|c|}{ r-metHuL } & \multirow[b]{2}{*}{$\begin{array}{c}\text { Total } \\
(n=284)\end{array}$} \\
\hline & & $\begin{array}{c}10 m g(a m) \\
(n=25)\end{array}$ & $\begin{array}{c}10 m g(p m) \\
(n=24)\end{array}$ & $\begin{array}{c}10 m g \text { BID } \\
(n=24)\end{array}$ & $\begin{array}{c}10 m g(a m) \\
(n=70)\end{array}$ & $\begin{array}{c}10 m g(p m) \\
(n=70)\end{array}$ & $\begin{array}{l}10 m g B I D \\
(n=71)\end{array}$ & \\
\hline Age (yrs) & Mean & $43.9 \pm 9.9$ & $49.5 \pm 8.6$ & $44.9 \pm 10.8$ & $47.0 \pm 9.9$ & $47.1 \pm 11.1$ & $47.0 \pm 10.9$ & $46.8 \pm 10.4$ \\
\hline Male & No. (\%) & $8(32 \%)$ & $9(38 \%)$ & $6(25 \%)$ & $28(40 \%)$ & $22(31 \%)$ & $23(32 \%)$ & $96(34 \%)$ \\
\hline Female & No. $(\%)$ & $17(68 \%)$ & $15(63 \%)$ & $18(75 \%)$ & $42(60 \%)$ & $48(69 \%)$ & $48(68 \%)$ & $188(66 \%)$ \\
\hline Weight (kg) & Mean & $94.7 \pm 15.3$ & $94.6 \pm 11.1$ & $91.1 \pm 12.8$ & $94.0 \pm 13.0$ & $92.6 \pm 12.2$ & $90.8 \pm 12.2$ & $92.7 \pm 12.6$ \\
\hline BMI & Mean & $32.7 \pm 2.9$ & $32.7 \pm 2.1$ & $31.7 \pm 2.8$ & $32.2 \pm 2.2$ & $32.3 \pm 2.4$ & $31.9 \pm 2.7$ & $32.2 \pm 2.5$ \\
\hline $\begin{array}{l}\text { Weight loss } \\
<2 \mathrm{~kg}^{*}\end{array}$ & No. (\%) & $11(44 \%)$ & $10(41.7 \%)$ & 10 (41.7\%) & $31(44.3 \%)$ & $30(42.9 \%)$ & $31(43.7 \%)$ & $123(43.3 \%)$ \\
\hline $\begin{array}{l}\text { Weight loss } \\
\geqq 2 \mathrm{~kg} 2 \mathrm{~kg}^{*}\end{array}$ & No. (\%) & $14(56 \%)$ & $14(58.3 \%)$ & 14 (58.3\%) & 39 (55.7\%) & 40 (57.1\%) & $40(56.3 \%)$ & $161(56.7 \%)$ \\
\hline
\end{tabular}

Values are mean \pm SD.

*Summarized based on levels of the randomization stratification factor during dietary weight loss period

metHuLeptin $\left(448 \pm 474 \mathrm{ng} \cdot \mathrm{mL}^{-1}\right)$ versus the placebo group $\left(18 \pm 13 \mathrm{ng} \cdot \mathrm{mL}^{-1}\right)$.

\section{DISCUSSION}

Leptin may play a role in obesity-related hypertension and alter vascular function. ${ }^{4,5} \mathrm{Few}$ data exist on the BP and vascular actions of leptin in humans to confirm this hypothesis. We have made one of the first attempts to address the relevance of this mechanistic pathway in humans by examining both the acute and chronic actions of exogenous leptin. Within hours, an increased plasma leptin level enhanced endothelial function (brachial FMD) in nonobese adults and did not alter BP. From the data that is available from a previously performed study, marked chronic hyperleptine- mia also did not appear to affect BP or heart rate in obese adults.

It has been hypothesized that selective leptin resistance, in the presence of chronic hyperleptinemia due to obesity, could promote hypertension. ${ }^{2}$ However, there is no direct evidence to support this hypothesis in humans. Cross-sectional studies linking BP, obesity, and leptin levels cannot discern physiologicallycausal roles from "innocent" associations. Intervention trials of exogenous leptin thus provide unique opportunities to directly address whether leptin per se plays a causal role in altering hemodynamics in humans. Our findings corroborate 2 prior experiments, which reported that leptin acutely enhances vasodilatory pathways in humans without altering BP over hours. ${ }^{7,8}$ Our current study is the first experiment to demonstrate that leptin enhances

Table 4. Weight and Blood Pressure Responses to Chronic Treatments

\begin{tabular}{|c|c|c|c|c|c|}
\hline & \multicolumn{2}{|c|}{ Baseline } & \multicolumn{2}{|c|}{ Change at Day 85} & \multirow[b]{2}{*}{$\mathrm{P}$} \\
\hline & r-metHuLeptin & Placebo & r-metHuLeptin & Placebo & \\
\hline Weight (kg) & $\begin{array}{l}92.6 \pm 12.4 \\
(n=208)\end{array}$ & $\begin{array}{c}93.5 \pm 13.1 \\
(\mathrm{n}=73)\end{array}$ & $\begin{array}{r}-3.2 \pm 3.7 \\
(\mathrm{n}=189)\end{array}$ & $\begin{array}{c}-2.9 \pm 3.2 \\
(\mathrm{n}=68)\end{array}$ & .54 \\
\hline SBP (mm Hg) & $\begin{array}{c}126.1 \pm 15.6 \\
(n=208)\end{array}$ & $\begin{array}{c}128.6 \pm 14.3 \\
(\mathrm{n}=72)\end{array}$ & $\begin{array}{c}-1.6 \pm 12.9 \\
(\mathrm{n}=187)\end{array}$ & $\begin{array}{c}-2.0 \pm 13.9 \\
(\mathrm{n}=67)\end{array}$ & .85 \\
\hline DBP (mm Hg) & $\begin{array}{c}77.2 \pm 9.5 \\
(\mathrm{n}=208)\end{array}$ & $\begin{array}{c}78.5 \pm 8.9 \\
(\mathrm{n}=72)\end{array}$ & $\begin{array}{r}-0.2 \pm 8.7 \\
(\mathrm{n}=187)\end{array}$ & $\begin{array}{c}-1.5 \pm 8.6 \\
(\mathrm{n}=67)\end{array}$ & .30 \\
\hline HR (beats $\cdot \min ^{-1}$ ) & $\begin{array}{l}69.9 \pm 9.8 \\
(\mathrm{n}=204)\end{array}$ & $\begin{array}{c}69.8 \pm 11.0 \\
(n=73)\end{array}$ & $\begin{array}{c}-1.4 \pm 10.7 \\
(\mathrm{n}=180)\end{array}$ & $\begin{array}{c}-1.4 \pm 10.4 \\
(\mathrm{n}=66)\end{array}$ & .98 \\
\hline
\end{tabular}

Values are mean \pm SD. Leptin group represents mean responses of all patients placed upon r-metHuLeptin at all doses.

$P=2$ samples t-test comparing day 85 changes between $r$-metHuLeptin and placebo groups

$\mathrm{n}=$ number of patients where measurement was made per group 
"endothelial function" as assessed by the standardized brachial FMD protocol. Moreover, the more relevant long-term hemodynamic actions of leptin have not been previously reported. In this analysis of the data from a previous chronic study, high dose r-metHuLeptin produced extreme hyperleptinemia, but did not significantly increase BP or heart rate compared to control patients with the same modest amount of weight loss. If high physiologic levels of leptin were contributing to elevated $\mathrm{BP}$ in humans, it would be expected that exogenous leptin would produce even further elevations in $\mathrm{BP}$, or at the very least blunt the hypotensive effect of the observed weight loss. This lack of a prohypertensive action of pharmacologically-induced chronic extreme hyperleptinemia, coupled with the confirmation that leptin acutely enhances endothelial function without altering BP, does not support the hypothesis that leptin per se directly plays a causal role in elevating BP in humans.

We recognize that our findings are the first attempt to specifically investigate both the acute and chronic effects of leptin on BP in humans. Therefore, there are several limitations in our studies that require these observations to be corroborated by future studies prior to making any definitive statement about the existence or nonexistence of a prohypertensive action of leptin. We cannot discount that the exogenous source of leptin and nonphysiologic plasma kinetics and marked plasma concentrations may not represent human (patho)physiology and may have contributed to our null findings. Since the weight loss in the leptin limb was not statistically greater than placebo, it is possible that the physiological actions of leptin were blunted in these patients (i.e., nonselective resistance). This may have contributed to a lack of a potential prohypertensive action. However, the particular advantages of these data are that they demonstrate that for equal degrees of weight loss, marked hyperleptinemia per se does not directly elevate BP. Finally, both studies were not specifically designed to detect small treatment differences in BP change. Larger studies using more sensitive techniques may uncover smaller effects missed in our studies (type 2 errors). However, even if a small effect were uncovered, it would not be consistent with leptin playing a major role in mediating obesity-related hypertension.

In summary, acute elevations in plasma leptin rapidly enhance conduit endothelial function as assessed by brachial FMD. We did not demonstrate that acute or chronic hyperleptinemia raises BP in healthy humans. More in-depth studies to confirm or refute a role for leptin in mediating obesity-hypertension in both lean and obese humans are clearly warranted based upon our initial findings.

\section{ACKNOWLEDGEMENT}

This study was funded by the General Clinical Research Center at the University of Michigan (MO1-RR00042) and Amgen Incorporated.

\section{REFERENCES}

1. Grassi G. Leptin, sympathetic nervous system, and baroreflex function. Curr Hypertens Rep 2004;6:236-240.

2. Mark AL, Correia MLG, Rahmouni K, Haynes WG. Selective leptin resistance: a new concept in leptin physiology with cardiovascular implications. L Hypertens 2002;20:1245-1250.

3. Ren J. Leptin and hyperleptinemia - from friend to foe for cardiovascular function. L Endocrin 2004; 181: 1-10.

4. Rahmouni K, Morgan DA, Morgan GM, Mark AL, Haynes WG. Role of selective leptin resistance in diet-induced obesity hypertension. Diabetes 2005;54:2012-2018.

5. Carlyle M, Jones OB, Kuo JJ, Hall JE. Chronic cardiovascular and renal actions of leptin. Role of adrenergic activity. Hypertension 2002;39:496-501.

6. Rajagopalan S, Brook RD, Rubenfire M, Pitt E, Young E, Pitt B. Abnormal brachial artery flow-mediated vasodilatation in young adults with major depression. Am J Cardiol 2001;88:196-198.

7. Nakagawa K, Higashi Y, Sasaki S, Oshima T, Matsuura $\mathrm{H}$, Chayama K. Leptin causes vasodilation in humans. Hypertens Res 2002;25:161-165.

8. Matsuda K, Teragawa H, Fukuda Y, Nakagawa K, Higashi $\mathrm{Y}, \mathrm{Chayama} \mathrm{K}$. Leptin causes nitric-oxide independent coronary artery vasodilation in humans. $\underline{H y}$ pertens Res 2003;26:147-152.

Address reprint requests to: Robert D Brook MD 24 Frank Lloyd Wright Dr. P.O. Box 322

Ann Arbor, MI, 48106-0739

E-mail: robdbrok@umich.edu 
This article has been cited by:

1. Yolanda E Bogaert, Stuart Linas. 2009. The role of obesity in the pathogenesis of hypertension. Nature Clinical Practice Nephrology 5:2, 101-111. [CrossRef] 